\title{
DIGITALCOMMONS
}

$@$ WAYNESTATE-

Wayne State University

$1-1-1998$

\section{Placing the Waitangi Tribunal: Attitudes Towards the Claims Settlement Process in New Zealand}

Kirsten Matoy Carlson

Wayne State University

\section{Recommended Citation}

Kirsten Carlson, Professor of Law, Placing the Waitangi Tribunal: Attitudes Towards the Claims Settlement Process in New Zealand, Address at the Critics \& Conscience: 5th National Postgraduate Conference (Dec. 6, 1998).

Available at: https://digitalcommons.wayne.edu/lawfrp/260 


\section{Placing the Waitangi Tribunal: \\ Attitudes towards the Claims Settlement Process \\ in Aotearoa New Zealand \\ by Kirsten S Matoy Carlson}

In 1975, the New Zealand Government passed the Treaty of Waitangi Act, establishing a commission of inquiry known as the Waitangi Tribunal to hear grievances against the Government in accordance with the 1840 Tiriti o Waitangi. According to the Government, "Under The Treaty of Waitangi Act (1975), the Tribunal is authorised to assess Maori claims. The Tribunal complements the work of the courts and political processes in this area.” (The Treaty of Waitangi Policy Unit 1990:1) There was nothing innovative about the Government's creation of a commission of inquiry to hear Maori grievances. The Waitangi Tribunal emerged out of a history of commissions of inquiry designed to resolve outstanding claims against the Government. Nor did the Government feel that it was doing anything innovative or new (Temm 1990:3). It was merely acquiescing to Maori demands and reluctantly agreeing to look into Maori grievances again.

In the past twenty-five years, the Waitangi Tribunal has emerged from the limited body devised by the Government in 1975 into a powerful part of the comprehensive Treaty Claims Settlement Process. Originally, the Tribunal was empowered by legislation only to hear claims against the Government starting after its creation in 1975. No historical claims could be brought before the Tribunal. Limitations such as this one, however, would change as the Tribunal's role in Aotearoa New Zealand society changed.

Noting the legal changes to the Waitangi Tribunal, the question becomes what the role of the Waitangi Tribunal is in Aotearoa New Zealand today. This analysis attempts to answer this question by looking at how the Aotearoa New Zealand public 
views the Waitangi Tribunal, the claims settlement process, and Maori-tauiwi relations.

\section{The Waitangi Tribunal and the Aotearoa New Zealand Public}

Interesting enough scholars Temm and Oliver believe that changes in public awareness of te Tiriti o Waitangi led to the creation of the Waitangi Tribunal. In setting out his purpose to explain what the Tribunal does to the masses, Oliver discusses how perceptions of te Tiriti have changed. He states, "The Treaty, then, mattered hardly at all to Pakeha politicians and public opinion for more than a century” (Oliver 1991:4). Temm also believes that few people had even heard of te Tiriti in the early 1970s (Temm 1990:3). Oliver continues on to purport that increased awareness both led to the creation of the Tribunal and has been promoted by the Tribunal. He explains, "However, by the 1970s the demand that the Treaty be respected and even heeded, and perhaps implemented, came to the fore. From this point of view, the creation of the Waitangi Tribunal in 1975 was a small and hesitant step in that direction” (Oliver 1991:9).

What both Temm and Oliver express is their personal insights into the reaction of the public to the Waitangi Tribunal. Neither scholar conducted research to determine how people react to the Tribunal or the claims settlement process. Outside of qualitative scholarly research, such as that conducted by Andrew Sharp and Paul McHugh, very little research has been done concerning the role of te Tiriti and the Tribunal in Aotearoa New Zealand society. Journalists Melbourne and Archie engaged in limited interviewing procedures to illicit attitudes towards Maori sovereignty and te Tiriti, but these interviews are limited by the lack of analysis that accompanies them. 
Despite the lack of data, the belief seems to exist among New Zealanders that the Tribunal has led to a polarisation of attitudes. ${ }^{1}$ More specifically, this polarisation is thought to occur along a cultural divide with Maori supporting the Tribunal and claims settlement process while non-Maori do not support the Tribunal and claims settlement process.

In order to determine the actual attitudes of citizens of Aotearoa New Zealand towards the Waitangi Tribunal, a quantitative study of the general Aotearoa New Zealand public was conducted. Using a survey design, the study tested whether attitudes towards the Tribunal, settlement process, and Maori sovereignty are affected by ethnic identification, gender, education, age, and knowledge or familiarity of such matters.

\section{Methodology}

The research followed a survey design. The survey included eight demographic questions measuring the independent variables of ethnicity, age, gender, rural/urban residency, district of residency in Aotearoa New Zealand, length of residence in Aotearoa New Zealand, and level of education. In addition to the demographic questions, independent variables were used to measure the selfidentified level of education of the respondents in relation to the Treaty of Waitangi, the Waitangi Tribunal, the Office of Treaty Settlements, and the Declaration of Independence 1835. These questions followed a Lickert scale design asking respondents whether they were very familiar, familiar, somewhat familiar, unfamiliar, or had never heard of each of the formerly listed documents or institutions. (Bernard 1995:297) These familiarity/knowledge questions were supplemented by questions regarding whether respondents had read the Treaty, if so what version (meaning 
language), how they know about the Waitangi Tribunal, and what they perceive sovereignty to mean.

The final category of questions comprised of Lickert scaled agree/disagree statements based on comments made in the interviews conducted by Archie and Melbourne. ${ }^{2}$ This adds an inductive as well as a deductive element to the survey in that each statement is based on something similar to what another New Zealander said. The statements cover a range of issues, including biculturalism, multiculturalism, colonisation, self-determination, Maori sovereignty, Maori protest, the Waitangi Tribunal, Maori protest, the Treaty of Waitangi, the Declaration of Independence, and full and final settlements. (A list of the survey questions can be seen in Appendix III).

The postal survey was sent out to a random sampling of Aotearoa New Zealand households with listed telephone numbers throughout both the North and South Islands. ${ }^{3}$ Of the 1000 surveys sent out, 440 were returned, including twenty which were unanswered. ${ }^{4}$

\section{Findings}

The survey findings indicate that although there is some polarisation among New Zealanders according to ethnicity on certain issues, for the most part, there is a lack of knowledge and/or informed opinions about sovereignty, Treaty, and Tribunal issues.

\section{Demographics}

The survey findings show the following demographic breakdowns. The sample appears representative in terms of age, gender and education (see Appendix 
IV for demographic breakdowns). In terms of ethnicity identified, the frequencies are less representative with a lower response rate (than population count) for Maori. Only $8.1 \%$ of respondents stated that they identified as Maori or part-Maori as compared with $12 \%$ of the general population. ${ }^{5}$ Additionally in terms of ethnicity, a number of European respondents took offense to the use of the term Pakeha. Of 322 respondents who identified themselves as New Zealand European or Pakeha, 38 crossed out the word Pakeha or noted that the word was derogatory. Similarly, a number of respondents checked the box labeled 'other' and wrote in New Zealander. Out of 36 responses marked 'other,' 20 were specified as New Zealanders. The demographic measures of urban/rural lifestyle and term of residency in New Zealand were deemed irrelevant as most people ticked city even if they lived in a town and almost all had resided in Aotearoa New Zealand for the majority of their lives.

\section{Percentage Distributions}

As shown in Table I, the frequency distributions calculated as percentages for the twenty-one Lickert scaled attitudinal measures show a range of positions rather than a clear polarisation of views among the Aotearoa New Zealand population. Contrary to the hypothesis of finding a consistent polarisation of views by ethnic group, the data does not show a clear polarisation across the attitudinal measures. The differences between perceptions by ethnicity emerges in the bivariate analysis.

The percentage distributions of the attitude measures indicate that New Zealanders have a range of opinions regarding ethnic relations. Certain attitudinal measures show a fair amount of general consensus. These attitudinal measures include Maori have a right to rule themselves, Parliament is the only governing power, settlements should be full and final, all New Zealanders should have equal 
rights, people do not know about the Declaration of Independence, the resolution of old injustices should not create new ones, and the Treaty is about co-existence and partnership. It is particularly interesting to note that $67 \%$ of the people surveyed agree that the Treaty of Waitangi is about partnership and co-existence.

Table I: Percentage Distribution of Attitude Measures ${ }^{6}$

\begin{tabular}{lccc}
\hline & Agree & Neutral & Disagree \\
\hline Attitude towards Waitangi Tribunal & 31.0 & 39.7 & 29.3 \\
Integrated biculturalism in NZ & 40.3 & 13.9 & 45.8 \\
Integrated multiculturalism in NZ & 66.9 & 13.8 & 19.3 \\
Colonisation as exploitation \& theft & 30.1 & 18.6 & 51.2 \\
Prevent new injustices & 80.7 & 8.1 & 9.0 \\
Waitangi Tribunal discriminates & 52.4 & 28.8 & 18.8 \\
Treaty about partnership & 67.2 & 17.0 & 15.8 \\
Maori sovereignty as critical issue to NZ & 23.5 & 21.4 & 55.1 \\
Lack of knowledge of Declaration of Indep. & 79.2 & 15.2 & 5.6 \\
Maori are sovereign indigenous people & 12.7 & 23.3 & 64.0 \\
Maori should not have rights over tauiwi & 66.5 & 13.8 & 19.7 \\
Loss of Maori culture without sovereignty & 19.6 & 13.1 & 67.0 \\
Historical justices should be put right & 52.6 & 18.3 & 29.1 \\
NZ ruined if Maori given sovereignty & 54.8 & 24.4 & 20.7 \\
Maori sovereignty means separatism & 36.9 & 19.6 & 43.6 \\
Everyone should have equal rights in NZ & 95.4 & 1.2 & 3.4 \\
Maori protest continue & 57.1 & 23.1 & 19.8 \\
Maori have right to rule themselves & 13.2 & 16.4 & 69.7 \\
Parliament only governing power in NZ & 80.4 & 8.6 & 11.0 \\
Sovereignty ceded under Treaty & 28.2 & 28.5 & 43.3 \\
Settlements should be full \& final & 75.1 & 12.4 & 12.4 \\
\hline
\end{tabular}

The percentage distributions also indicate that there is a range of disagreement on specific measures, including those related to attitudes towards the work of the Waitangi Tribunal, biculturalism, Maori sovereignty as meaning Maori separatism, whether sovereignty was ceded under the Treaty, whether historical injustices should be put right, and whether or not New Zealand would be ruined if Maori were given sovereignty. It is interesting to note the split in attitude towards the Tribunal as people are almost equally opposed to and in favour of it. 
There is also a high number of neutral responses. Taken with the percentage distributions of the knowledge measures, the high number of neutral responses could indicate a lack of knowledge on the part of most New Zealanders when it comes to sovereignty, Treaty, and Tribunal issues. The percentage distributions of the knowledge measures can be seen in Table II. The high percentages of neutral response may also indicate that people are not concerned about sovereignty, Treaty, and Tribunal issues.

Table II: Percentage Distribution of Knowledge Measures

\begin{tabular}{cccccc}
\hline & $\begin{array}{c}\text { never } \\
\text { heard of it }\end{array}$ & unfamiliar & $\begin{array}{c}\text { somewha } \\
\text { t familiar }\end{array}$ & familiar & $\begin{array}{c}\text { very } \\
\text { familiar }\end{array}$ \\
\hline $\begin{array}{c}\text { Treaty of } \\
\text { Waitangi }\end{array}$ & -- & 17.2 & 51.8 & 24.2 & 6.8 \\
$\begin{array}{l}\text { Waitangi } \\
\text { Tribunal }\end{array}$ & 1.0 & 27.1 & 53.3 & 16.9 & 1.7 \\
$\begin{array}{c}\text { Office of Treaty } \\
\text { Settlements }\end{array}$ & 10.0 & 47.3 & 31.7 & 9.8 & 1.2 \\
$\begin{array}{c}\text { Declaration of } \\
\text { Independence }\end{array}$ & 19.4 & 45.6 & 23.0 & 11.0 & 1.0 \\
\hline
\end{tabular}

Table II shows that most respondents are at least somewhat familiar with the Treaty of Waitangi and the Waitangi Tribunal. Familiarity levels decrease by about $20 \%$ however when it comes to the Office of Treaty Settlements and the Declaration of Independence and over half the respondents say they are unfamiliar with these. Of particular interest is the fact that everyone says that they have heard of the Treaty of Waitangi. However, only $29.8 \%$ of those surveyed indicated that they had read the Treaty of Waitangi. Overall, this indicates that the majority of New Zealanders are only nominally aware of the Treaty, the Waitangi Tribunal, and sovereignty issues.

In terms of assessing the knowledge levels of New Zealanders, it is also interesting to look at how they defined sovereignty. Five options were listed for respondents to choose from, including 'never thought about it.' Fourteen percent of 
respondents stated that they had never thought about what sovereignty means. Of the $85.75 \%$ of respondents who selected a definition of sovereignty, $32.5 \%$ indicated that sovereignty means 'supreme power as defined by the constitutional law of those subject to the power'; $10.5 \%$ defined sovereignty as 'a final and absolute authority in the political community’; $29.1 \%$ as 'sovereignty is being in control of one’s self . . . being able to be part of life, to live life, and to have aspirations and goals and meet them'; and $14.3 \%$ selected 'sovereignty is our ability to determine our own destiny in terms of our land and our fisheries.' Also of interest is the fact that more respondents chose not to answer this question than any other question on the survey. This indicates that respondents are unclear as to what sovereignty means and how to answer the question. Further, the response breakdowns show that there is not a clear consensus concerning what sovereignty means.

Additionally, an aggregate level of knowledge was developed from the four initial familiarity questions regarding the Treaty of Waitangi, Waitangi Tribunal, Office of Treaty Settlements, and Declaration of Independence. The percentage distribution for the aggregate measure of knowledge can be seen in Table III.

Table III: Aggregate Measure of Familiarity Questions

\begin{tabular}{lc}
\hline Level of Aggregate Familiarly & Percentage \\
\hline Unfamiliar & 17.4 \\
Somewhat familiar & 59.8 \\
Familiar & 20.1 \\
Very familiar & 2.7 \\
\hline
\end{tabular}

As Table III indicates the respondents do not perceive themselves as very familiar or knowledgeable about the Treaty of Waitangi, the Waitangi Tribunal, the Office of Treaty Settlements, and the Declaration of Independence. Most respondents, 59.8\% indicate that they have some familiarity of these issues and 
organisations, but do not consider themselves to be very familiar with or very knowledgeable of them.

A final interesting point to be uncovered in the data concerning respondents familiarity with claims settlement issues exists in how they responded to the question, “If you have heard of the Waitangi Tribunal, how do you know about it?” Six options were listed under this question, including newspaper, school/work, kaumatua, TV/radio news, friends/peers, and other. Table IV shows how respondents answered this question.

\section{Table IV: How Respondents Know about the Waitangi Tribunal}

\begin{tabular}{cc}
\hline Source & Percentage Accessing Source \\
\hline Newspaper & 78.3 \\
School/work & 25.6 \\
Kaumatua & 4.7 \\
TV/radio news & 86.7 \\
Friends/peers & 29.1 \\
Others & 8.9 \\
\hline
\end{tabular}

As evident in Table IV, the most relied on sources of information regarding the Waitangi Tribunal are newspapers and television/radio news. High percentages of respondents (78.3\% for newspapers and $86.7 \%$ for TV/radio news) indicated that the news media provided them with information on the Tribunal. These percentages are more than double that of the next source, which was friends/peers.

Recalling that this analysis focuses on whether or not there is a polarisation of views in Aotearoa New Zealand concerning sovereignty issues and the claims settlement process, bivariate analyses were performed to determine how respondents’ views varied by ethnicity. As the bivariate analysis is discussed, it is important to keep in mind that the majority of the respondents indicated that they had not read the 
Treaty of Waitangi and were not familiar with the Treaty, the Tribunal, the Office of Treaty Settlements, and the claims settlement process in general.

\section{Bivariate Analysis}

The bivariate analysis is based on contingency table analysis. Three different trends emerge in the contingency tables. First, it becomes apparent that New Zealand European and New Zealand Maori respondents are split in their opinions when it comes to particular attitudinal measures. The second phenomenon shows opinions moving in the same direction regardless of ethnicity but with different strengths of opinion underlying those trends. In these measures, the degrees of decay differ significantly; the opinions of one ethnic group descend more rapidly from agree to disagree or from disagree to agree than the opinions of the other ethnic group. The final trend exists within the first two and indicates that individuals identifying as 'other' show the most resistance to sovereignty issues and the claims settlement process.

In looking at the first trend, notable polarisation of opinion by ethnicity occur in the following variables: Maori are a sovereign indigenous people, sovereignty was ceded under the Treaty, New Zealand will be ruined if Maori are given sovereignty, sovereignty is a critical issue, and the Waitangi Tribunal discriminates against nonMaori. Tables $\mathrm{V}$ through IX show the breakdown of opinions by ethnicity by percentage for these variables.

Table V: Sovereignty is Critical to New Zealand's Future By Ethnicity ${ }^{7}$ 


\begin{tabular}{lccccc}
\hline & Asian & NZ European & NZ Maori & Pacific Islands & Other \\
\hline Disagree & 30.7 & 59.1 & 28.1 & -- & 54.3 \\
Neutral & 53.8 & 20.1 & 21.8 & 25 & 25.7 \\
Agree & 15.3 & 20.8 & 50 & 75 & 20 \\
\hline
\end{tabular}

Chi Sq. $=.00$

Table VI: Maori are a Sovereign Indigenous People By Ethnicity

\begin{tabular}{lccccc}
\hline & Asian & NZ European & NZ Maori & Pacific Islands & Other \\
\hline Disagree & 61.5 & 66.2 & 32.3 & 75 & 65.7 \\
Neutral & 23.1 & 22.7 & 25.8 & -- & 31.4 \\
Agree & 15.3 & 11.1 & 41.9 & 25 & 2.8 \\
\hline
\end{tabular}

Chi Sq. $=.00$

Table VII: Sovereignty Was Ceded Under the Treaty of Waitangi By Ethnicity

\begin{tabular}{lccccc}
\hline & Asian & NZ European & NZ Maori & Pacific Islands & Other \\
\hline Disagree & 23 & 27.3 & 46.9 & 50 & 17.1 \\
Neutral & 38.5 & 26.3 & 28.1 & 50 & 42.8 \\
Agree & 38.5 & 46.3 & 25.0 & -- & 40 \\
\hline
\end{tabular}

Chi Sq. $=.04$

Table VIII: NZ will be Ruined if Maori are given Sovereignty By Ethnicity

\begin{tabular}{lccccc}
\hline & Asian & NZ European & NZ Maori & Pacific Islands & Other \\
\hline Disagree & 15.3 & 19 & 51.6 & 75 & 5.8 \\
Neutral & 38.4 & 24.7 & 19.3 & -- & 26.5 \\
Agree & 46.1 & 56.1 & 29 & 25 & 67.7 \\
\hline
\end{tabular}

Chi Sq. $=.00$

Table IX: The Waitangi Tribunal Discriminates Against Non-Maori By Ethnicity

\begin{tabular}{lccccc}
\hline & Asian & NZ European & NZ Maori & Pacific Islands & Other \\
\hline Disagree & 15.3 & 17.6 & 45.1 & 75 & 5.8 \\
Neutral & 69.2 & 27.3 & 32.2 & 25 & 25.7 \\
Agree & 15.3 & 55.0 & 22.5 & -- & 68.5 \\
\hline
\end{tabular}

Chi Sq. $=.00$

The polarisation by ethnicity, particularly New Zealand European and New Zealand Maori, across these five variables is almost equal. For instance, on the question of whether or not sovereignty issues are critical to the future of New 
Zealand, 59.1\% of New Zealand European respondents indicate that it is not, where $50 \%$ of New Zealand Maori say that it is. This trend flows through all the variables. What is interesting, however, is that the responses consistently show that New Zealand Maori feel that sovereignty is a critical issue, that Maori have valid claims, and that they are competent of governing. With the exception of the question concerning whether or not sovereignty was ceded under the Treaty of Waitangi, this trend is significant at the .00 level. Thus, the relationship between each variable and ethnicity is highly significant. Consequently, it is more than likely that these polarisations are representative of the Aotearoa New Zealand population as a whole.

The second trend that occurs is that Maori and New Zealand European attitudes indicates that there is not a polarisation of views by ethnicity across all the attitudinal variables. This trend is interesting because one would not assume to find it after finding the first trend. The second trend undermines the idea that there is a strict polarisation of views across the variables. It becomes clear that Maori are not strictly for the claims settlement process while non-Maori are not strictly against it.

In four variables, the attitudes follow the same direction, but the strength of that direction differs by ethnicity. This trend occurs in the variables pertaining to attitudes towards the work of the Waitangi Tribunal, historical injustices being put right, settlements being full and final, and Maori being allowed self-determination. Tables $\mathrm{X}$ through XIII show the interrelationships between these variables and ethnicity.

Table X: Attitude Towards the Waitangi Tribunal's Work By Ethnicity ${ }^{8}$

\begin{tabular}{l|ccccc}
\hline & Asian & NZ European & NZ Maori & Pacific Islands & Other \\
\hline Disagree & 27.3 & 27.8 & 18.8 & -- & 54.3 \\
Neutral & 63.6 & 39.3 & 37.5 & 50 & 34.3
\end{tabular}




\begin{tabular}{l|lllll} 
Agree & 9.1 & 32.9 & 43.7 & 50 & 11.4 \\
\hline & & & & Chi Sq. $=.00$
\end{tabular}

Table XI: Historical Injustices Should be put Right By Ethnicity

\begin{tabular}{l|ccccc}
\hline & Asian & NZ European & NZ Maori & Pacific Islands & Other \\
\hline Disagree & 23.1 & 28.3 & 6.3 & 25 & 61.8 \\
Neutral & 23.1 & 17.3 & 28.1 & -- & 14.7 \\
Agree & 53.8 & 54.4 & 65.6 & 75 & 23.5 \\
\hline
\end{tabular}

Chi Sq. $=.00$

Table XII: Claims Settlements should be Full and Final By Ethnicity

\begin{tabular}{l|ccccc}
\hline & Asian & NZ European & NZ Maori & Pacific Islands & Other \\
\hline Disagree & 38.5 & 11.6 & 18.2 & -- & 8.3 \\
Neutral & 30.7 & 10.0 & 24.2 & 25 & 13.9 \\
Agree & 30.7 & 78.4 & 57.6 & 75 & 77.8 \\
\hline
\end{tabular}

Chi Sq. $=.00$

Table XIII: Maori have a Right to Rule Themselves By Ethnicity

\begin{tabular}{l|ccccc}
\hline & Asian & NZ European & NZ Maori & Pacific Islands & Other \\
\hline Disagree & 38.5 & 73.3 & 40.0 & 50 & 77.1 \\
Neutral & 38.5 & 15.2 & 23.3 & 25 & 17.1 \\
Agree & 23.0 & 11.4 & 36.7 & 25 & 5.7 \\
\hline
\end{tabular}

Chi Sq. $=.00$

In analysing the data in Tables $\mathrm{X}$ through XIII, several interesting patterns occur. With the exception of Table X, it becomes clear that more Maori than New Zealand Europeans are neutral or uncertain of their opinions on these issues. In Tables XII and XIII the strength of the decay towards disagreement with the issue is stronger for New Zealand Europeans than for Maori. This is exceedingly clear in Table XIII where the Maori respondents appear to be more polarised in their views with only $40 \%$ disagreeing with the statement that Maori people have a right to rule themselves as compared with $73.3 \%$ of New Zealand Europeans. The results in Table XII are similar, only there seems to be a smaller degree of polarisation within the Maori sample. Conversely, Table XI shows a stronger decay within the Maori sample 
towards agreement with the statement 'historical injustices should be put right' than in the New Zealand European sample.

Finally, Table X may prove the most interesting as it indicates a fair amount of polarisation not across ethnic categories, but within them. The New Zealand European sample is almost evenly split as to whether they agree or disagree with the work of the Waitangi Tribunal with the largest number of respondents, 39.3\%, saying that they were neutral. A similar effect can be perceived within the Maori sampling only to a lesser degree. Ultimately, among Maori, more agree with the work of the Waitangi Tribunal than disagree or are neutral. The relationships indicated by Tables $\mathrm{X}$ to XIII also prove extremely significant and can be seen as representing the general Aotearoa New Zealand public.

The final trend emerges in both of the previously discussed trends. The trend is that people who identify themselves as other, almost two-thirds of whom specify themselves as 'New Zealanders,' tend to have opinions opposite to Maori. The strength of decay towards disagreeing with the statements is also stronger than those seen in the New Zealand European and Maori samplings. In Tables VI, VIII, IX, X, and XIII, the strength of decay for the 'other' category differs markedly from that of New Zealand Europeans in that fewer 'others' agree with the statements. Almost all these tables also indicate that more 'others' than New Zealand Europeans disagree with the statements. Further, in Tables X and XI, the 'others' sampling trends against both those of Maori and New Zealand Europeans showing that their views move in the opposite direction from the rest of those surveyed.

Noting that a high percentage of those who identified as 'other' also specified that they were 'New Zealanders' and that their attitudes tend to polarize most strongly with Maori and even New Zealand Europeans, the hypothesis can be suggested that 
the majority of this category is made up of New Zealanders of European descent. Further, these New Zealanders appear to be the most opposed to the claims settlement process and negative towards Maori issues in general.

\section{Multivariate Analysis}

Three kinds of multivariate analysis were run, including correlation matrices, log-linear analyses, and classification trees. First, a correlation matrix was devised to determine the relationships between the attitudinal variables. The correlation matrix found that using Bonferroni’s Adjusted p-values several variables correlated at the 0.00 level. However, none of these correlations showed strong relationships (all relationships were below the .5 level). Five of the variables in particular did not correlate with the other variables. These were 'we live in an integrated bicultural society'; 'we live in an integrated multicultural society'; 'in resolving old injustices, the Government needs to prevent new injustices’; the Treaty is about co-existence and partnership'; and 'most people do not know about the Declaration of Independence.'

The second multivariate analysis consisted of log linear models. Nine log linear models were run. Six of these models indicated that significant relationships did not exist between the variables. These models included: knowledge or familiarity level by education by ethnicity; attitude towards the work of the Waitangi Tribunal by knowledge or familiarity level by education by ethnicity; knowledge or familiarity level by sovereignty is critical to the future of New Zealand by Maori should be a sovereign indigenous people by ethnicity; knowledge level by ethnicity by attitude towards the Tribunal by Treaty settlements should be full and final; knowledge level by ethnicity by sovereignty is critical to the future of New Zealand; and knowledge level by ethnicity by settlements should be full and final. 
Two log-linear models indicated a significant three way interaction at the 0.02 level. These were ethnicity by knowledge level by attitude towards the work of the Waitangi Tribunal and sovereignty is critical to the future of New Zealand by Maori should be a sovereign indigenous people by ethnicity. The final log-linear model, attitude towards the Tribunal by ethnicity by settlements should be full and final, was significant at the 0.00 level. Tables XIV through Table XXV show the relationships indicated by the log linear models.

Table XIV: Attitude towards the Waitangi Tribunal by Knowledge Level

\begin{tabular}{cccc}
\hline & Agree & Neutral & Disagree \\
\hline Unknowledgeable & 15 & 63 & 22 \\
Somewhat Knowledgeable & 32 & 41 & 27 \\
Knowledgeable & 42 & 22 & 36 \\
Very Knowledgeable & 55 & 18 & 27 \\
\hline
\end{tabular}

The global analysis of attitude towards the Waitangi Tribunal by knowledge level indicates that as knowledge levels increase so does approval of the work of the Waitangi Tribunal. The question then becomes what the trends look like for each individual ethnicity. ${ }^{9}$ Tables XV through XVII show attitude towards the Tribunal by knowledge level by ethnicity.

Table XV: Attitude towards the Tribunal by Knowledge Level for New Zealand Europeans

\begin{tabular}{cccc}
\hline & Agree & Neutral & Disagree \\
\hline Unknowledgeable & 19 & 57 & 24 \\
Somewhat Knowledgeable & 35 & 41 & 24 \\
Knowledgeable & 42 & 24 & 34 \\
Very Knowledgeable & 24 & 24 & 42 \\
\hline
\end{tabular}

Table XVI: Attitude towards the Tribunal by Knowledge Level for New Zealand Maori 


\begin{tabular}{cccc}
\hline & Agree & Neutral & Disagree \\
\hline Unknowledgeable & -- & 100 & -- \\
Somewhat Knowledgeable & 29 & 47 & 24 \\
Knowledgeable & 64 & 18 & 18 \\
Very Knowledgeable & 100 & -- & -- \\
\hline
\end{tabular}

Table XVII: Attitude towards the Tribunal by Knowledge Level for Other

\begin{tabular}{cccc}
\hline & Agree & Neutral & Disagree \\
\hline Unknowledgeable & -- & 90 & 10 \\
Somewhat Knowledgeable & 15 & 36 & 48 \\
Knowledgeable & -- & -- & 100 \\
Very Knowledgeable & 100 & -- & -- \\
\hline
\end{tabular}

When divided by ethnicity, it becomes evident that Maori tend to be more in favour of the Tribunal as their knowledge level increases where New Zealand Europeans tend to be less in favour of the Tribunal as their knowledge level increases. Although the trends for the 'other' category seem to resemble those of the New Zealand European category, it is not altogether clear what is going on there. Tables XVIII through XXI show the log linear model for sovereignty is critical to New Zealand's future by Maori should be a sovereign indigenous people by ethnicity.

Table XVIII: Sovereignty is Critical to New Zealand's Future by Maori should be a Sovereign Indigenous People

\begin{tabular}{cccc}
\hline & Disagree & Neutral & Agree \\
\hline Disagree & 77 & 16 & 16 \\
Neutral & 13 & 47 & 18 \\
Agree & 10 & 37 & 66 \\
\hline
\end{tabular}

As the global bivariate analysis for sovereignty is critical to New Zealand's future by Maori should be a sovereign indigenous people shows, respondents tend to polarize into groups either agreeing with both statements or disagreeing with both 
statements. The breakdown of the analysis by ethnicity can be seen in Tables XIX through XXI.

Table XIX: Sovereignty is Critical to New Zealand's Future by Maori should be a Sovereign Indigenous People for New Zealand Europeans

\begin{tabular}{lccc}
\hline & Disagree & Neutral & Agree \\
\hline Disagree & 81 & 14 & 24 \\
Neutral & 10 & 49 & 20 \\
Agree & 9 & 37 & 56 \\
\hline
\end{tabular}

Table XX: Sovereignty is Critical to New Zealand's Future by Maori should be a Sovereign Indigenous People for New Zealand Maori

\begin{tabular}{lccc}
\hline & Disagree & Neutral & Agree \\
\hline Disagree & 80 & -- & -- \\
Neutral & 10 & 50 & 15 \\
Agree & 10 & 50 & 85 \\
\hline
\end{tabular}

Table XXI: Sovereignty is Critical to New Zealand's Future by Maori should be a Sovereign Indigenous People for Other

\begin{tabular}{lccc}
\hline & Disagree & Neutral & Agree \\
\hline Disagree & 53 & 36 & -- \\
Neutral & 32 & 36 & 25 \\
Agree & 15 & 28 & 75 \\
\hline
\end{tabular}

Tables XIX, XX, and XXI indicate that the strength of the global trend varies by ethnicity. Maori are the most likely to be polarised into either agreeing or disagreeing with both statements. New Zealand Europeans (81\%) tend to disagree with both statements more while more 'others' (75\%) appear to agree with both statements.

The final significant log linear model run was attitude towards the work of the Waitangi Tribunal by settlements should be full and final by ethnicity. Table XXII 
shows the global bivariate results for attitude towards the work of the Waitangi Tribunal by full and final settlements.

Table XXII: Attitude towards the Tribunal by Full and Final Settlements

\begin{tabular}{lccc}
\hline & Agree & Neutral & Disagree \\
\hline Disagree & 30 & 24 & 32 \\
Neutral & 37 & 55 & 40 \\
Agree & 33 & 21 & 28 \\
\hline
\end{tabular}

The global analysis indicates that there is a fairly even split in attitudes towards the Tribunal regardless of how respondents feel about full and final settlements. Tables XXIII through XXV show what happens when ethnicity is added to the equation.

Table XXIII: Attitude towards the Tribunal by Full and Final Settlements for New Zealand Europeans

\begin{tabular}{lccc}
\hline & Agree & Neutral & Disagree \\
\hline Disagree & 27 & 16 & 41 \\
Neutral & 38 & 58 & 32 \\
Agree & 35 & 26 & 27 \\
\hline
\end{tabular}

Table XXIV: Attitude towards the Tribunal by Full and Final Settlements for New Zealand Maori

\begin{tabular}{lccc}
\hline & Agree & Neutral & Disagree \\
\hline Disagree & 11 & 50 & -- \\
Neutral & 39 & 37 & 33 \\
Agree & 50 & 13 & 67 \\
\hline
\end{tabular}

Table XXV: Attitude towards the Tribunal by Full and Final Settlements for Other

Agree Neutral Disagree




\begin{tabular}{llll} 
Disagree & 56 & 28 & 14 \\
Neutral & 29 & 71 & 86 \\
Agree & 15 & 29 & -- \\
\hline
\end{tabular}

Adding ethnicity to the bivariate model for attitude towards the work of the Waitangi Tribunal by full and final settlements shows that where New Zealand Europeans are more likely to agree with both statements, New Zealand Maori are more likely to agree with the work of the Waitangi Tribunal and disagree with the statement that settlements should be full and final. The data almost suggests that for New Zealand Europeans the work of the Waitangi Tribunal is conditional upon full and final settlements.

The final multivariate analysis which was run consisted of four classification trees. Classification trees were created for ethnicity, knowledge, gender, and education. Although none of the classification trees indicated a viable way in which to classify respondents by any of the above listed demographic variables, some trends of interest were apparent from them. Before discussing the underlying trends evident in the classification trees, it is essential to note the significance in the fact that none of the classification trees proved capable of classifying the respondents. This is significant because it indicates that the views of respondents are not clearly polarised by gender, ethnicity, knowledge level, or educational level.

The classification trees for ethnicity and knowledge show behavioral trends. The ethnicity classification tree indicates that respondents who disagreed that 'everyone in New Zealand should have equal rights' were almost ten times more likely to be New Zealand Maori than New Zealand European. The classification tree for knowledge shows that respondents who agree with the statement 'Maori are a 
sovereign indigenous people' tend to have higher levels of knowledge than those who disagree with that statement.

The multivariate analysis builds upon the bivariate analysis by indicating relationships between more than two variables. Following the conclusions of the bivariate analysis, the multivariate analysis does not provide any evidence for a strict polarisation of views by ethnicity. This is particularly evident in the fact that predictive classification trees cannot be created for the data.

\section{Comments}

In addition to the statistical data generated by the surveys, a number of respondents chose to add comments at the end of the survey. Almost $30 \%$ of the participants wrote comments on the survey. The types of comments written on the surveys can be divided into four groups: those urging that the results be made public, 'thank yous' for the opportunity to participate in the survey and promoting thought and discussion about the issues presented, complaints concerning the survey, and comments concerning the issues mentioned in the survey. This analysis will focus on the comments regarding the issues presented in the survey as they are the most relevant.

The comments regarding issues can be divided into categories. The first two categories, sovereignty/tino rangatiratanga and injustices, are closely interrelated. The third category is history and the education system. There are three other interesting commentaries which arise in the comments. These are collectively listed as miscellaneous. They include: one on the differentiation between views in the South and North Island; another on the term "Pakeha"; and finally one on the place of Maori in Aotearoa New Zealand society today. 


\section{Sovereignty/Tino Rangatiratanga}

The comments which pertain to sovereignty/tino rangatiratanga issues indicate that many New Zealanders do not understand what sovereignty means, either in a European context or a Maori one. This leaves many people uncertain as to what to think and how to respond to these issues. An Auckland respondent writes,

My main problem is with the definition of sovereignty. In my view the term most appropriately applies to countries being independent of other countries. Sovereign power resides in the government, parliament, ruler or strongman.

Queen Elizabeth is referred to as the sovereign, but has no power to govern. We would hardly call a dictator a sovereign.

Maori sovereignty is used in different ways too. One extreme view is that advocated by Syd Jackson and others, who mean government by Maori only over all New Zealanders.

What I believe it to mean for most Maori and many Pakeha is selfdetermination, in which Maori decide on and do things for Maori using both their own resources and those provided by the state.

Other respondents also feel that a number of meanings are assigned to different uses of the term sovereignty.

A man in his thirties from Christchurch who identifies himself as a New Zealand European explains that he really does not know what to think about sovereignty. He purports,

I daresay I seem to have contradicted myself here and there but that probably best sums up my overall ambivalence to sovereignty issues. I support 'some degree' of Maori sovereignty (if that's possible), but tend to think that real partnership and power-sharing is the best way forward.

This man not only discusses his own uncertainty about sovereignty issues, but he also indicates that the concern should be on how the country develops in the future rather than focusing on past issues.

A woman in her fifties from Ngaruawahia who also identifies herself as a New Zealand European supports this view. She writes,

I don't believe sovereignty is the issue. Injustice has been done, but reparation and then forgiveness needs to be a part of it. 
Most people hear the word sovereignty and define it as rule but we each have choices individually and this is what will make or break this country. People whatever the culture need to stop looking back in the past and look to the future -- working united towards making New Zealand the country it could be.

This respondent comments, like the other two men quoted, about how people should be working towards the future. She, however, unlike the men, does not see sovereignty or self-determination as a vital part of this process. All three appear to agree that once historical injustices are resolved, New Zealand can reconcile its differences and work to strengthen itself.

Another respondent fears that sovereignty issues will lead to the demise of the Aotearoa New Zealand state. An Asian Aucklander in his early twenties writes,

I believe that the Maori people have suffered injustices. And I believe these should be redressed by the proper means. But I strongly object to Maori forming their own sovereign and independent state within New Zealand. It is difficult for two culturally different nations to be living side by side especially if the newly formed nation was created in reaction to perceived oppression. The Balkan crisis is a striking example of this.

This man expresses a fear that many other respondents hint at -- that Maori selfdetermination can only be recognised as long as it does not undermine the Aotearoa New Zealand state. This view is evident in comments like 'limited forms of Maori sovereignty.' The fears underlying these comments can easily be explained by the lack of knowledge that respondents acknowledge they have about sovereignty issues and the claims settlement process.

The sheer anger and fear that arise out of misinformation and misunderstanding of sovereignty issues and Maori culture in general can be seen in this comment by an Auckland woman in her forties who identifies as a New Zealand European. She states,

If Maori culture was a worthwhile and descent [sic] way of life . . . the European settlers would and could have lived by their law, but it was a hard 
primitive life which meant uncertainties every day -- who was going to be attacked next -- savagery of indescribable torture, not to law breakers but to every man, woman, and child who was caught up in it.

I wish the Maori would just thank the British law for bringing them out of their stoneage lifestyle -- nothing is perfect -- but I sure feel happier under British law. The Maori had many hundreds of years to get it right before the European came, but 'might was right' in those days -- not 'right is might.' I feel sorry for those pushing this Maori sovereignty issue. Can you imagine life under Maori sovereignty? Gasp. Horror.

Obviously, cultural misunderstandings persist in Aotearoa New Zealand.

From the comments written about sovereignty issues, it is evident that a lack of knowledge about the claims settlement process and sovereignty issues leads individuals to be confused and/or unclear as to how to react to these issues. Further, it provokes some individuals to be concerned about the idea that Maori sovereignty or self-determination could lead to the demise of the Aotearoa New Zealand state. As becomes clear in the previous chapters, the demise of the Aotearoa New Zealand state is not universally advocated by Maori or necessarily perceived as a part of rangatiratanga.

The general consensus emerging out of the comments made about sovereignty seems to be that all people in Aotearoa New Zealand need to be working together. This view is epitomised by the respondent who writes,

An aspect of sovereignty that all people but especially Maori will need to explore further concerns New Zealand tomorrow in the management of our national resources, helping recognize our strengths, helping build the models that will create our economy and fashion the thinking for a new millennium.

This individual summarises the view of most of the other respondents in urging Maori and tauiwi to work together to acknowledge the attributes that all ethnicities bring to the Aotearoa New Zealand state and to find and use the models which are most profitable.

\section{Injustices}


The second subject heavily commented upon by respondents is that of injustices. This issue provokes highly emotive responses from some individuals. A demographically unidentifiable respondent writes,

There have been injustices throughout the world as a result of colonisation. You cannot revise history. New Zealanders are a very non-aggressive race sympathetic to Maori claims but at some stage enough is enough. I strongly believe that Maori should get on with improving their lot by improving themselves and stop blaming other people -- that weakens their own ability to do better in society.

This respondents' opinion is reiterated by a man in his late twenties from Dunedin who identifies himself as a New Zealander. He insists,

New Zealand cannot afford to settle claims that are exorbitant. There are no full blooded Maori in New Zealand therefore their claim is against some of their own ancestry. Do we pay in proportion? . . . I agree the Maori have not been honoured through the treaty. But I am not responsible for my forefathers and neighbours' crimes.

The anger brought out by the claims settlement process and the recognition of injustices created by the Government against Maori does not end there.

Expressing a similar view an Asian male from Auckland states, "I think all Maori protest is nonsense, and it should stop. After so many years, the Maori should not have the right of claim over land.” His comments are supported by a woman in her sixties from Tauranga who identifies as a New Zealand European. She explains,

I am becoming more and more angry at the millions of dollars being paid out to the Maoris and their never-ending claims at a time when New Zealand is fighting to fend off economic recession and the government say we cannot afford a decent health system or police or fire services to protect every citizen (and that includes Maoris).

These negative comments towards the acknowledgment of injustices by the Government and restoration of mana to Maori through the claims settlement process indicate that those who oppose the claims settlement process are very vocal about it. 
Even more extreme views, however, exist. One person who sent the survey back, refused to answer the survey, but did write the following comments. The individual wrote,

The Treaty is creating separatism, scrap the damn thing before New Zealand ends up like old South Africa. It is unreasonable to expect the present generation to atone for the past, real or imagined. New Zealand is a nation of many, many races. We all have a right to live in peace, those of us born here are Tangata Whenua, regardless of our colour. Learn to live with it. Burn the Treaty and dismantle the Tribunal.

Comments such as this, indicate the depth of emotion individuals feel about the claims settlement process. Further, these negative sentiments show that the lack of knowledge that individuals have about the process and why it is occurring leads people to react emotively rather than rationally.

Not all respondents have such harsh comments to make about injustices and the claims settlement process. Respondents with a more positive perspective on the claims settlement process tend to see it as a way to unify all cultures in Aotearoa New Zealand. An Auckland male in his thirties who identifies as a New Zealand European writes,

Perhaps typical of my white middle class background, I possess ignorance of real Maori issues. I think: -there can only be one parliament -Maori people were probably ripped off under the Treaty and -some compensation is due.

-Maori culture is important to New Zealand and must not be allowed to die. I, as a New Zealander am proud of the Maori culture and being a New Zealander.

-History is full of bloody, dishonest takeovers.

One should not dwell too much on history, except to move forward, that is why I support a full and final settlement for claims. In many countries/cultures recompense has never been made.

This respondent while admitting his ignorance, looks at the claims settlement process as something that is necessary to bring Maori and tauiwi together in Aotearoa New Zealand. His view does not stand alone. 
A Gisborne man in his forties who identifies himself as New Zealand European "and not proud of it" believes that the Treaty needs to be rewritten. He states,

I'm Pakeha and back Maori where possible because of the shameful and disgusting things people like Captain Crook and other so called well meaning foreigners have done to Maori. . . . The Treaty needs to be rewritten in New Zealand by New Zealanders and Maori without the Queen's two cents. She knows nothing of this country or its workings.

This man's comment is unique not only because he requests that the Treaty be rewritten but because he asserts that it is Aotearoa New Zealand's issue, for Aotearoa New Zealand and everyone in it, to sort out.

A man in his late twenties from Nelson who identifies as half Maori, half European has a slightly different perspective on these issues. He writes,

To obtain a nation where every New Zealander has equal opportunity and respect, everyone should forgive and forget. I believe a wrong may of been done years ago but why now divide the population by payouts (which admit nothing) we cannot as a country afford. We need to live as many cultures not as any one culture running the other.

Although this respondent fears that the claims settlement process has the potential to tear the nation in two, he also believes that the country needs to acknowledge the place of its many cultures. Similarly another respondent states, “New Zealanders and Maori need to face the past and not be afraid to do so but also need to face the future as an international state in the South Pacific.”

The views of respondents towards the subject of injustices and the claims settlement process vary from extremely negative to positive. Most of the responses, however, indicate an underlying emotive response to the process which stems from the lack of knowledge that people have about it.

\section{History and Education}


Closely related to issues concerning the injustices being acknowledged by the Crown through the claims settlement process are questions concerning the history of Aotearoa New Zealand and the education of New Zealanders. As with the comments written about injustices, many of these responses are emotive rather than based on a clear understanding of the Treaty of Waitangi or the claims settlement process.

Similar to the comments made about injustices and the claims settlement process, some respondents had negative views on the impact the claims settlement process has had on history in Aotearoa New Zealand. Representative of these views, a woman from Whakatane who identifies as a New Zealand European in her late twenties writes,

Although I have not read the Treaty, I make my comments under the influence of my up-bringing, which was to treat everyone the same, to get along with things, live with history and not try to change it.

I strongly feel that New Zealand Maori would benefit most from learning their history and culture not trying to get a free ride from it. I'm sure we could all do this if we wanted to -- why are Maori so special in today's society?

Even though this woman admits to being uninformed about the Treaty, she feels that she can express her opinion on New Zealand history and the claims settlement process because it raises an emotional response from her. She does not understand either New Zealand history nor the place of the Maori within it because she has never been educated in these matters.

Another woman in her fifties from Auckland who identifies herself as a New Zealander expresses the view that the claims settlement process is attempting to rewrite history. She writes, "It seems that a few are twisting history to their own advantage. I am not responsible for the actions of generations of people who I never knew. History is history.” The comments made by this woman not only insist that history cannot be added to or rewritten but hark back to comments made by other 
respondents about feeling responsible or guilty for the actions of previous generations. This view shows the misunderstanding that the claims settlement process is about relationships between individuals rather than between iwi and the Government.

The lack of education concerning Aotearoa New Zealand history and the claims settlement process arises as a major part of the comments made by respondents. Some respondents admit their own lack of knowledge about these issues. One woman in her forties from Christchurch who identifies as a New Zealand European writes, "Participating in this survey made me very aware of just how little I know about the Treaty of Waitangi, the history of events concerning it, current issues surrounding it, and the Waitangi Tribunal and the work they do.” Another woman from Pekapeka who is over 70 years of age and identifies as a New Zealand European found herself in a similar situation. She explains,

On the issue of sovereignty I feel I do not sufficiently understand the Maori viewpoint or how they mean it to work. I think a great deal of misunderstanding arises from the differences between oral and written traditions, and the fact that 'objective history' has only been written since about 1920. Before that most history was partisan.

Not only does this woman feel that she doesn't know enough about 'the Maori viewpoint' but she also thinks that most other New Zealanders are in the same situation because of the lack of education taught on these matters. Similarly, an Auckland man in his fifties who identifies himself as a New Zealand European purports, "New Zealanders have not been adequately consulted on this matter.”

Another common response from respondents emerges in the number of calls for increased education on these matters. An Auckland woman in her thirties who identifies as a New Zealand European explains, 
There obviously needs to be more public information/education re declaration of independence, office of Treaty Settlements (which I had never heard of) and the Waitangi Tribunal and Treaty of Waitangi via the media in an informed non-confrontational style (is such a thing possible?).

Her view is supported by a Ngati Raukawa woman in her thirties from Palmerston North. She states, “All children should be taught about the Treaty of Waitangi and the Declaration of Independence in our schools. Misinformation given by uninformed people breeds anger and violence towards issues about the Treaty of Waitangi.” This view is reiterated by a Atimounuiapaparangi woman in her thirties from Wanganui. She explains,

I think, or rather I know, that the Treaty of Waitangi should be taught in our schools full on. I mean right from scratch. Today's society only knows what we were allowed to know. As a New Zealand Maori, I strongly believe that every New Zealander has the right to know the truth of what the Treaty involves and how our Government has not kept to the promises that were drawn up over 150 years ago.

As aptly put by this respondent, people have a right to know the truth and that alone should be the impetus for educating New Zealanders.

From the comments made by respondents it becomes evident that misinformation and ignorance promote emotive rather than informed attitudes and raises tensions between ethnic groups.

\section{Miscellaneous}

Aside from the comments which serve to represent the main kinds of comments written on the surveys, three other comments are of particular interest. The first discusses the term 'Pakeha,' the second the possible differences between views according to region, and the third, Maori culture.

This man's comments on the use of the term 'Pakeha' are particularly telling because of the number of respondents who indicated that the term was offensive. The man who is from Christchurch, is over 70 years old, and identifies himself as a New 
Zealand European. He writes, "I believe that the word 'Pakeha' be dropped from all official documents when referring to New Zealand citizens other than Maori. I would sooner be called a Kiwi as I feel the word 'Pakeha' is a word of hate when spoken in some circumstances.” Interestingly enough no one comments on the use of the term 'Maori' or the fact that it was created at the same time as the term 'Pakeha.'

The second individual comment of interest regards regional differences. A New Zealand European gentleman over 70 years of ago who resides in Christchurch explains,

Most South Island respondents, whether of European or Maori background will view the survey differently from North Island respondents.

There are very strong feelings in many parts of the South Island, against Maori claims; my experience is that most Europeans and many Maori have very little understanding or knowledge of New Zealand history and don't want to know the actual facts.

Although this respondent feels that emotive responses that are not related to the factual history of Aotearoa New Zealand are particular to the South Island, the survey data indicates that this is true throughout both islands.

The final comment of interest comes for a Hamilton woman in her thirties who identifies as a New Zealand European. She sarcastically comments on the Aotearoa New Zealand state and its view towards Maori culture. She states,

New Zealand as a nation currently relies upon the oppression of Maori and, ironically, the valourisation of a mythical Maori. We as a nation in today's world requires a Maori who represent an authenticity of culture, but who cannot be allowed to be real, make mistakes or have power. We need Maori to stay put on marae -- go back to marae.

The woman's comment which sounds vaguely familiar to other ones is that Maori are accepted within New Zealand society only so long as they are good and quiet and stay on their marae. This suggests the level of discomfort that tauiwi feel towards Maoritanga yet their desire to retain the image of having the 'best' race relations in 
the world. Comments made in the section on injustices clearly show that this is not true.

\section{Conclusions}

The findings of this survey indicate that the general Aotearoa New Zealand public does not know much about the Treaty of Waitangi, the Waitangi Tribunal, or the claims settlement process. Despite this lack of knowledge, there is some support for what the Government is doing through the process. Since the Government is dedicating time and resources, it is quite concerning that the general public does not know much about the claims settlement process. ${ }^{10}$

The situation is even more problematic when one analyses the rhetoric of the Waitangi Tribunal towards the education of the general public. Looking at the Tribunal's and OTS's stance on educating the public shows how dedicated the Government really is to the claims settlement process.

The Waitangi Tribunal’s 1998 Business Strategy Report states, “We aim to promote an understanding of the principles of the Treaty of Waitangi and the role and processes of the Waitangi Tribunal” (The Waitangi Tribunal 1998:25). Under the subheading “How We Will Do It,” the report explains,

3.1 We will review strategies to assist in the education of the public on the processes of the Tribunal and, more generally, on Treaty-related matters.

3.2 We will seek to disseminate widely the reports of the Tribunal as a means of promoting the principles of the Treaty and an understanding of the whole claims process. The reports will be disseminated through a range of media and the process will be ongoing. (The Waitangi Tribunal 1998:25-26)

The fact that New Zealanders do not seem very aware of the claims process indicates that the Tribunal is not fulfilling this aim. Further, the dedication of the Tribunal to 
this aim becomes even more questionable when one considers the cost and bulk of its reports, which makes them highly inaccessible to the general public. (For instance, the Taranaki Report costs about \$100.) To date, the Tribunal, when compared to other educational promotions made by the Government (including the drunk driving campaign) has made very limited efforts to inform the general public of its work and the reason behind its existence.

The hesitancy on the part of the Government to commit itself to informing the public about the claims settlement process is also evident through the actions and attitudes of the Office of Treaty Settlements. When asked by Taranaki iwi claimant Mereana Hond about educating the public about the claims settlement process during a speech at Victoria University, Doug Graham, the Minister of Treaty Settlements, responded with a comment on sending out brochures by mail and how ineffective this would be. Graham did not indicate that a more complete or personal way of informing the public, such as through television advertisements, educational classes, or regional council meetings, was an option. It seems indicting that the New Zealand Government spends millions of dollars promoting safe driving and retirement funds, but refuses to even attempt explaining the claims settlement process muchless positive intercultural relations to its constituents. This seems to go not only against the Government's rhetoric about educating the public but also against its commitment to resolving grievances through the claims settlement process.

The Government's failure to educate the public about the claims settlement process indicates that the Government is not committed to moving beyond its history of colonial policies and attitudes and towards promoting a society where every culture is equally valued. As the research shows, this undermines both the claims settlement process and relationships between Maori and tauiwi. 
${ }^{1}$ The only research uncovered which actually looked at attitudes of the general public towards the Treaty was conducted by Te Papa Tongarewa prior to the creation of its 'Signs of a Nation' exhibit. This research has not been released to the public and so will not be discussed. The reason given as to why the material has not been released was that it showed a polarisation of attitudes and racist views which were thought to be more detrimental than beneficial.

2 The actual phrasing of the questions differ from the direct quotes taken by Melbourne and Archie. They are similar in content though.

${ }^{3}$ Telecom generated a list of 1000 randomly selected households with listed telephone numbers for this survey.

${ }^{4}$ Twenty of the returned surveys were not completed; explanations as to why the surveys were not answered accompanied most of these. Reasons for returning the survey unanswered ranged from "Too old to worry about this" and "we are not interested in participating" to "Burn the Treaty and Dismantle the Tribunal." Since almost 5\% of the total number of surveys were returned unanswered, it is significant to note that active non-participants -- people who obviously do not want to express their attitudes towards the Treaty, the Tribunal and the claims settlement process -- exist within Aotearoa New Zealand society.

${ }^{5}$ Due to the expectation that fewer Maori would respond to the survey, anyone who identified him/herself as of Maori descent was included in the Maori category. Please note that several respondents identified themselves as both Maori and European.

${ }^{6}$ The valid percentages, which have been adjusted to exclude missing values, have been used in all tables.

${ }^{7}$ Due to the small numbers of Pacific Islanders and Asians in the survey, the ethnic categories were collapsed and the cross tabulations rerun. The secondary runs indicated that the relationships were still significant. The Chi squares are as listed by abbreviated variable names.

sovcede by ethnicity $=.01$, indigene by ethnicity $=.00$, critical by ethnicity $=.00$, ruined by ethnicity $=$ .00 , discriminate by ethnicity $=.00$

${ }^{8}$ For the same reason, secondary runs were also performed on these variables. The significance levels for the secondary runs are listed below as chi squares by abbreviated variable names.

selfrule by ethnicity $=.00$, attitude by ethnicity $=.01$, fullfine by ethnicity $=.03$, attitude by ethnicity $=$ .00 .

${ }^{9}$ Due to the small numbers of respondents in the Asian and Pacific Islands categories, they were amalgamated into the other category for the log linear modeling.

${ }^{10}$ Questions remain as to whether or not the Government is dedicating enough time and resources to the claims settlement process. Many Maori do not feel that the Government is doing as much as it should be. 